\title{
Conflict of Interest - Serious Issue on Publication Ethics for Indian Medical Journals
}

Kusal K Das, ${ }^{1}$ Tejaswini Vallabha, ${ }^{2}$ Jaydeb Ray, ${ }^{3}$ P S N Murthy ${ }^{4}$

'Department of Physiology, ${ }^{2}$ Department of Surgery, BLDE University's Sri B.M. Patil Medical College, Bijapur-586103, Karnataka, India, ${ }^{3}$ Institute of Child Health, Kolkata-700017, India, ${ }^{4}$ Department of E.N.T. and Head and Neck Surgery, Dr. P.S. Institute of Medical Sciences and R.F., Gannavaram, A.P, India.

\section{ABSTRACT}

Introduction: There are several vested interest lies on research publication hence the editorial policy is the sole important factor to control and regulate ethical publications in medical sciences especially on 'conflict of interest' issue. The study was aimed to assess on awareness of 'conflict of interest' issue in medical research and publication among the editorial staff, peer reviewers and authors of Indian medical journals.

Methods: Total 61 authors who have published research articles recently in Indian medical journals from 2008-2012, 56 peer reviewers who reviewed the manuscripts during same period and 35 editorial board members of various Indian medical journals were assessed by questionnaire and telephone interview regarding their understanding and knowledge on 'conflict of interest' issue for ethical publication.

Results: Only seven (12\%) of the authors knew about the 'conflict of interest' issue and $11(19 \%)$ of the medical authors have just heard about it. Out of $12 \%$ of authors who knew 'conflict of interest' issue only $15 \%$ provided that statement to the journals. Among the peer reviewers only $17(30 \%)$ knew about 'conflict of interest' of which 51 (91.5\%) stated that they do not bother about this issue while reviewing the manuscripts. But interestingly $42(75 \%)$ of the peer reviewers confessed that they had a bias on the topics written by their friends or students. Among the editorial board members of Indian medical journals only 14 (25\%) have any idea on 'conflict of interest issue'.

Conclusions: Results clearly shows poor understanding of 'conflict of interest' like important ethical issue among Indian medical scientists or journals.

Keywords: authors; conflict of Interest; editorial members; peer reviewers; Indian Medical Journals.

\section{INTRODUCTION}

Among the various types of complications are faced by academic journal- the most difficulty for an Indian journal is facing today is the 'conflict of interest'. There are several vested interests lies in research publication and hence the editorial policy is the only important factor in controlling and regulating ethical publications in medical sciences especially with regard to 'Conflict of Interest' (COI). A conflict of interest exists when an

Correspondence: Dr. Kusal K. Das, Professor of Physiology, BLDE University Sri B.M.Patil Medical College \& Research Centre, BLDE University, Bijapur 586103, Karnataka, India. Email: kusaldas@yahoo. com, Phone: 918352272067. 
Das et al. Conflict of Interest - Serious Issue on Publication Ethics for Indian Medical Journals

individual's professional or ethical obligations might be compromised by self-interest. ${ }^{1}$

$\mathrm{COI}$ in medical publishing affects everyone with a stake in research integrity including journals, research/ academic institutions, funding agencies, the popular media, and the public. Conflicts of interest increase the temptation to commit misconduct. ${ }^{2}$ If the potential gain is large, however, then principles that guide responsible conduct in research may be compromised. The International Committee of Medical Journal Editors has recommended both to authors and editors that financial associations that may pose a conflict of interest should be disclosed. ${ }^{3}$

Hence, the study was aimed to assess on awareness of the 'conflict of interest' issue in medical research and publication among the editorial staff, peer reviewers and authors of Indian medical journals.

\section{METHODS}

A descriptive study from march, 2011 to December, 2012 was conducted to ascertain what percentage of Indian medical journals editorial board members, peer reviewers and authors of Indian nationality had knowledge and understanding of $\mathrm{COI}$, we have selected a study sample as following:-

Number of Indian Journals consulted $(n=15)$; Authors $(n=61)$; Peer Reviewers $(n=56)$ and Editorial Board Members $(n=35)$.

All the journals which are considered for the study are indexed in Pubmed/Scopus/EMBASE/Chemical Abstract. Authors are considered based on their published articles in per article per corresponding author. Peer reviewers were selected by telephonic and email contact from this investigator's contact list and they are not Editorial Members of any journals. Editorial Board members are also selected by present investigator's contact list and net searching. They may be peer reviewers too. Identity of the journals, authors, peer reviewers and editorial members were kept confidential. Figure 1 shows the distribution of authors, peer reviewers and editorial board members among Indian medical journal editors in preclinical (Physiology, Biochemistry, Anatomy), para-clinical (Pharmacology, Pathology, Microbiology, Forensic Medicine etc.) and clinical subjects (Medicine, Surgery, Obstetric \& Gynecology, Pediatrics, Orthopedics, Otorhinolaryngeology etc).

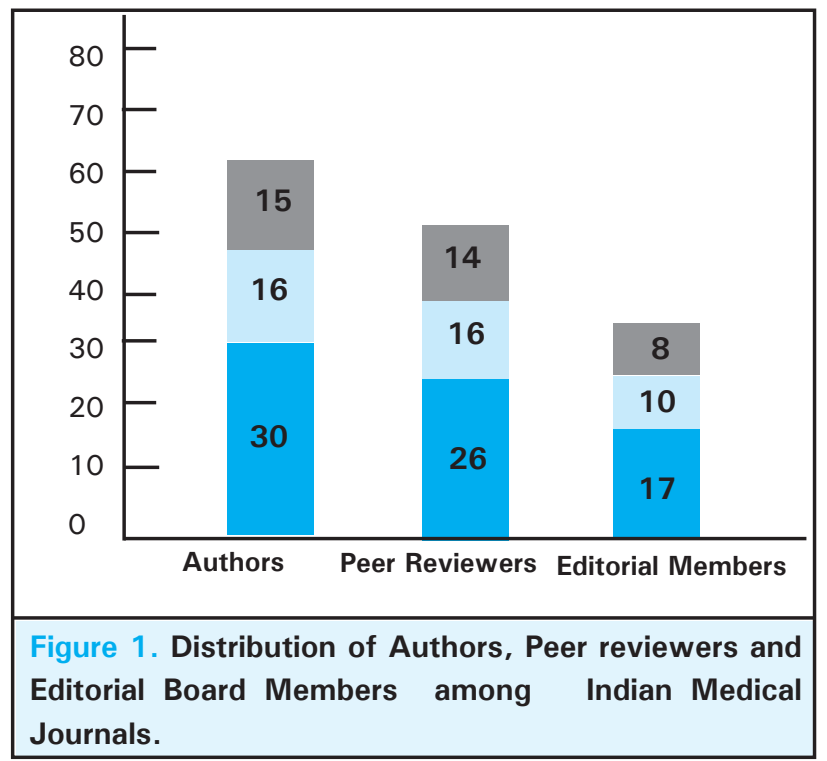

We have prepared questionnaire and telephone interview regarding their understanding and knowledge on 'conflict of interest' issues for ethical publication. The Questions are simple and straight forward (Table 1-3).

\section{RESULTS}

The most of the authors $50(81 \%)$ never heard of 'conflict of interest' issue and they least bother to notice that in journal $42(70 \%)$. Interestingly majority of authors 54 (88\%) have no idea about it. Total $12 \%$ of authors who knew 'conflict of interest' issue only $15 \%$ provided that statement to the journals (Table 1 ).

\begin{tabular}{|lllll|}
\hline Table 1. Questionnaire and responses from authors $(\mathbf{n}=\mathbf{6 1})$. & & & \\
\hline S.N. & Question & Yes, $\mathbf{n}(\%)$ & No, n (\%) & Never verified \\
1. & $\begin{array}{l}\text { Do authors notice "COI" statement" in "Instruction to } \\
\text { Author" section of journal? }\end{array}$ & $12(20 \%)$ & $42(70 \%)$ & $7(10 \%)$ \\
2. & Does author heard of "COI"? & $11(19 \%)$ & $50(81 \%)$ & - \\
3. & Does author has any idea about "COI" meaning? & $7(12 \%)$ & $54(88 \%)$ & - \\
4. & $\begin{array}{l}\text { Does author provide or declare his /her" COI"(who knows } \\
\text { about COI)? (n=07) }\end{array}$ & $1(15 \%)$ & $6(85 \%)$ & - \\
5. & $\begin{array}{l}\text { Does editor asks "COI" declaration from the authors after } \\
\text { acceptance of article (if not provided)? }\end{array}$ & $7(11 \%)$ & $54(89 \%)$ & - \\
\hline
\end{tabular}


Das et al. Conflict of Interest - Serious Issue on Publication Ethics for Indian Medical Journals

It is also surprising that $24(42 \%)$ of peer reviewers and 20 (58\%) of medical journal editorial board members too did not hear about 'conflict of interest' issue (Table 2, 3).

Table 2. Questionnaire and responses from Peer reviewers $(n=56)$.

\begin{tabular}{|c|c|c|c|c|}
\hline S.N. & Question & Yes, n (\%) & No, $n(\%)$ & Not answered \\
\hline 1. & Do peer reviewers heard of "COI": & $32(57 \%)$ & $24(42 \%)$ & - \\
\hline 2. & Do peer reviewers know "COI" meaning? & $17(30 \%)$ & $34(61 \%)$ & $5(9 \%)$ \\
\hline $2 a$ & $\begin{array}{l}\text { Do peer reviewers verify/check the same in the } \\
\text { manuscript accordingly? } n=17 \text { (yes) }\end{array}$ & $01(6 \%)$ & $16(94 \%)$ & - \\
\hline $2 b$ & $\begin{array}{l}\text { Have peer reviewers ever returned/rejected a manuscript } \\
\text { based on potential financial COI? } n=17 \text { (yes) }\end{array}$ & $0(0 \%)$ & $17(100 \%)$ & - \\
\hline 4. & $\begin{array}{l}\text { Do peer reviewers review the manuscript if the author's } \\
\text { identity is disclosed and found that it happens to be their } \\
\text { friends or students? }\end{array}$ & $42(75 \%)$ & $12(21 \%)$ & $2(4 \%)$ \\
\hline 5. & $\begin{array}{l}\text { Do editorial office ever inquire about } \mathrm{CO} \text { issue on article } \\
\text { which peer reviewers were asked to review? }\end{array}$ & $5(9 \%)$ & $51(91 \%)$ & - \\
\hline
\end{tabular}

Table 3. Questionnaire and responses from Editorial Board Members $(n=35)$.

\begin{tabular}{|c|c|c|c|c|}
\hline S.N. & Question & Yes, n (\%) & No, n (\%) & Not answered \\
\hline 1. & $\begin{array}{l}\text { Do editorial board members were aware of } \mathrm{COI} \text { issue in } \\
\text { research publication? }\end{array}$ & $9(25 \%)$ & $20(58 \%)$ & $6(17 \%)$ \\
\hline 2. & $\begin{array}{l}\text { Have editorial board members ever asked / discussed about } \\
\text { this issue with editors or publishers? }\end{array}$ & $5(14 \%)$ & $27(77 \%)$ & $3(9 \%)$ \\
\hline
\end{tabular}

More interestingly, even the peer reviewers who knew about 'conflict of interest' issue hardly bother to verify the

statement of that in manuscript $16(94 \%)$ and returned the manuscript on possible potential COI 17 (100\%). It is also interesting to know that majority 42 (75\%) of peer reviewers have confessed that they review the manuscript even after knowing that the author is either their colleague/friend or students (Table 2). Fifty one (91\%) peer reviewers and 27 (77\%) editorial board members said that neither they nor editorial office have ever interact with each other on this $\mathrm{COI}$ issue.

The medical journals have better understanding on COI issue than editorial board members (30\% vs $25 \%$ ) (Figure 2).

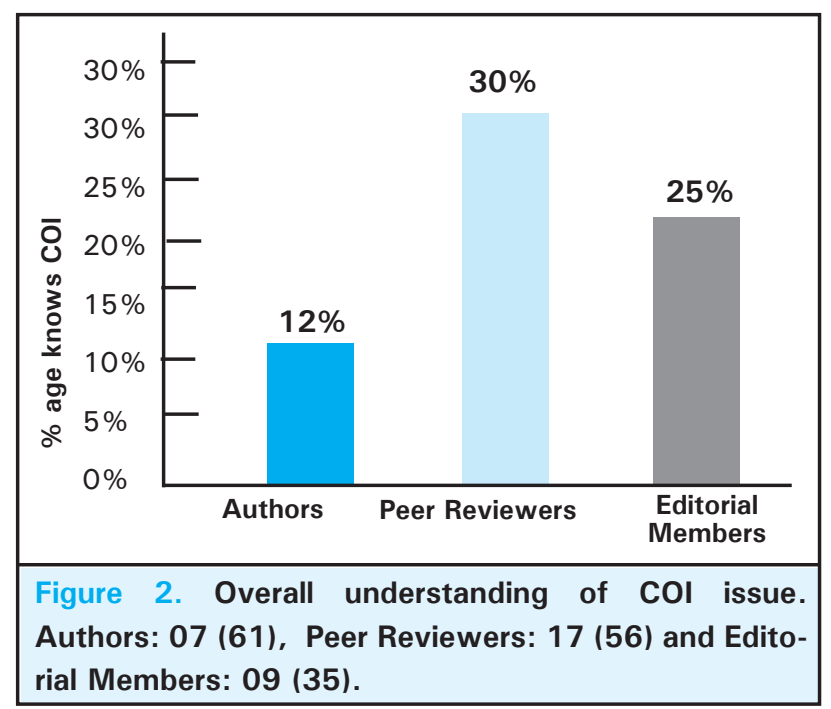




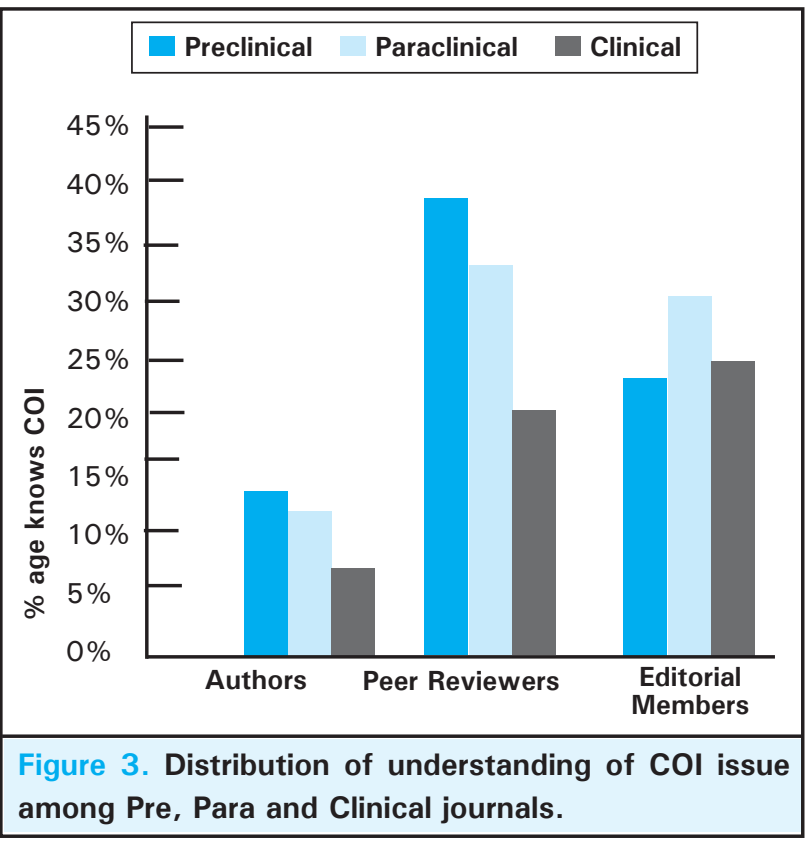

The distribution of understanding of $\mathrm{COI}$ issue among Pre, Para and Clinical journals in India are varies (Figure 3 ). The results clearly indicate that authors and peer reviewers of pre-clinical medical journals are slightly better aware than their para-clinical and clinical counterparts whereas among editorial board members the para-clinical members are found to be better aware on conflict of interest issue in medical journals.

\section{DISCUSSION}

The results clearly show the poor understanding of this important ethical issue among Indian medical scientists and journals. The problem of 'conflict of interest' is very common in Indian medical journals. Most of the medical institutions in India receive hardly any government research funds but publication is mandatory for their survival. In this context the influence of the pharmaceutical industry on medical research has been a major ethical issue on 'conflict of interest'. In 2009 a study found that "a number of academic institutions" do not have clear guidelines for relationships between Institutional Review Boards and industry. ${ }^{4}$ Although the "Publish or Perish" situation is not that serious in Indian scenario but once again the promotion policy of faculty members in medical or scientific institutions is strongly based on research publications as per University Grants Commission (UGC) and Medical Council of India (MCI) guidelines.

Poor infrastructure, lack of support from universities or government organizations, very weak ethical regulations (many institutions do not even have a proper institutional regulatory board) cast a shadow on ethical research in medicine and leads to multiple conflicts of interest in publications. In the complex scenario of medical publication, Indian medical journals need to pay more serious attention to publication ethics, especially 'conflict of interest'. Probably regular workshops either in person or online, training for peer reviewers and editorial board members may help in improving this issue. Prior screening of peer reviewers and editorial board members before selection/election of these groups may be a good option if journals take a serious call on this. Authorities of medical journals and medical institutions should come forward and handle these ethical challenges together.

\section{ACKNOWLEDGEMENT}

The first author gratefully acknowledges 'Committee on Publication Ethics', U.K. for providing him 'COPE International Scholarship 2012' to present his research works on publication ethics in London at COPE European Seminar 2012.

\section{REFERENCES}

1. MacDonald C, McDonald M, Norman W. Charitable Conflicts of Interest. J Business Ethics. 2002; 39:67-74.

2. Williams-Jones B, Mcdonald J. Conflict of Interest Policies at Canadian Universities: Clarity and Content. J Acad Ethics. 2008;6:79-90.
3. International Committee of Medical Journal Editors Conflicts of interest. Lancet. 1993;341:742-3.

4. Lexchin J, Bero LA, Djulbegovic B, Clark O. Pharmaceutical industry sponsorship and research outcome and quality: systematic review. BMJ. 2003;26:1167-70. 